\title{
Implante de peritônio homólogo conservado após ceratectomia lamelar em cães
}

\author{
Preserved homologous peritoneum graft after lamellar \\ keratectomy in dogs
}

Jair de Almeida GARCIA'; Paulo Sérgio de Moraes BARROS'; José Luiz LAUS ${ }^{2}$; Afonso Luiz FERREIRA ${ }^{3}$; Angelica Mendonça Vaz SAFATLE

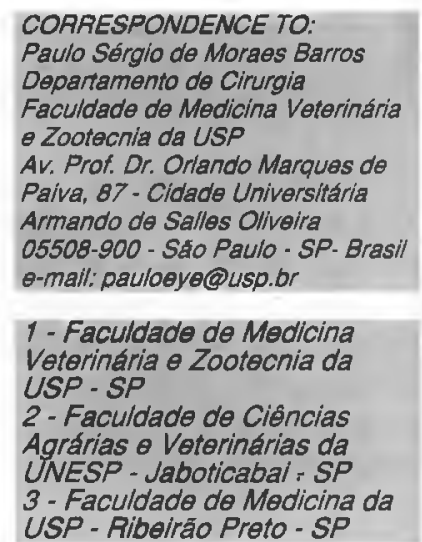

\section{RESUMO}

\begin{abstract}
Estudou-se a viabilidade do uso do peritônio homólogo, conservado em glicerina, na reparação de lesões superficiais da córnea, após ceratectomia lamelar. Para tanto foram utilizados 7 cães, machos e fêmeas, pesando $10 \mathrm{~kg}$ em média. Realizou-se ceratectomia lamelar de $0,4 \times 0,5 \mathrm{~mm}$ de lado e $1 / 3$ da espessura da córnea, bilateralmente, e no mesmo período anestésico, seguida de implante de peritônio homólogo e utilizando-se sutura interrompida aplicada em toda a extensão do enxerto. Os animais foram sacrificados e seus globos oculares enucleados, em intervalos de 24 horas, 7, 15, 30 e 60 dias de pós-operatório. Para observação dos resultados, procedeu-se às avaliações clínica e histológica. Blefarospasmo, quemose e opacidade de córnea foram sinais comuns aos períodos precoces de pósoperatório, os quais foram desaparecendo até o $32^{\circ}$ dia, quando o enxerto se encontrava em plena fase de desopacificação e o globo ocular isento de sinais de inflamação. Epitelização total do enxerto se fez presente aos sete dias, seguida por reabsorção do mesmo, com ausência de infiltrado inflamatório aos 17 dias. Houve deposição de pigmento no estroma nos períodos tardios de avaliação. Não foi observado infiltrado inflamatório nem reação clínica que pudesse ser patognomônica de eliminação do enxerto. Diante das observações factuais de cada um dos tempos, admite-se o emprego do peritônio homólogo na reparação lamelar de lesões superficiais da córnea, constituindo-se, portanto, em mais uma opção de técnica de ceratoplastia no cão.
\end{abstract}

UNITERMOS: Córnea; Enxerto; Cães; Peritônio; Transplante de córnea.

\section{INTRODUÇÃO E REVISÃO DE LITERATURA}

$\longrightarrow$ eratites ulcerativas resultantes de condições destrutivas, infecciosas ou não, são entidades freqüentes e importantes na oftalmologia, em face da sua alta morbidade. Anormalidades palpebrais, ciliares, do aparelho lacrimal, e também de traumas, constituem os principais fatores ligados à gênese do processo ${ }^{17,25,31,35}$.

Com o intuito de restabelecer prontamente o tecido corneano lesado, tratamentos clínicos e cirúrgicos têm sido amplamente propostos. No atinente ao tratamento cirúrgico, destacam-se os recobrimentos com $3^{3}$ pálpebra ${ }^{2.15 .21 .24}$, enxertos conjuntivais pediculados ou não ${ }^{12,13,19,23,32,33,37}$ e aplicação de $\operatorname{adesivos}^{22,28}$, além de transposição córneo-escleral ${ }^{20,26,27,30}$. Aplicação de lentes de contato ${ }^{14,16}$, transplante de córnea com tecidos autólogos e homólogos ${ }^{7,10,11}$, além de implantes sintéticos ${ }^{8,36}$, têm sido igualmente contemplados.

Ainda no que concerne às opçōes de reparaçāo, periósteo autólogo ${ }^{18}$ e películas de celulose $\mathrm{e}^{29}$ foram também estudados.

As membranas biológicas têm sido alvo de experimentação com resultados animadores incluindo-se nesse rol o uso de pericárdio homólogo e xenólogo em vários órgãos ${ }^{1,34}$.

Em oftalmologia veterinária essa mesma membrana foi empregada na correção cirúrgica de entrópio e preenchimento de cavidade orbitária de cães após enucleação ${ }^{3}$, bem como na reparação de defeitos lamelares de esclera e $3^{\text {a }}$ pálpebra, também na espécie canina ${ }^{4}$ e ainda na ceratoplastia penetrante após remoção de neoplasia ${ }^{5}$.

Experimentalmente o pericárdio foi utilizado por Barros et $a l .{ }^{6}$ (1992) como enxerto em lesões penetrantes e lamelares da córnea de cāes, com resultados satisfatórios. O uso de peritônio homólogo encontra citação em esofagoplastias ${ }^{9}$. Em contrapartida, o seu emprego em oftalmologia veterinária ainda não foi experimentado.

Neste trabalho objetivamos estudar a viabilidade de utilização experimental do peritônio homólogo conservado em 
GARCIA, J.A.; BARROS, P.S.M.; LAUS, J.L.; FERREIRA, A.L.; SAFATLE, A.M.V. Implante de peritônio homólogo conservado após ceratectomia lamelar em cães. Braz. J. vet. Res. anim. Sci. São Paulo, v.33, supl., p.290-294, 1996.

glicerina em ceratoplastias lamelares em cães.

\section{MATERIAL E MÉTODO}

\section{Animais}

Foram utilizados 7 cães machos e fêmeas, sem raça definida, adultos, pesando em média $10 \mathrm{~kg}$, considerados clinicamente sadios, os quais permaneceram em canis individuais.

Submeteram-se os animais a exame clínico geral e oftalmológico prévio, incluindo biomicroscopia, tonometria, teste de lágrima de Schirmer, teste de fluoresceína e oftalmoscopia direta.

Os enxertos foram implantados bilateralmente, no mesmo período anestésico, sendo os animais sacrificados em intervalos de 24 horas, $7,15,30$ e 60 dias de pós-operatório, sendo 2 olhos por tempo, totalizando 14 córneas.

\section{Procedimento cirúrgico}

Realizadas as medidas pré-operatórias pertinentes, procedeu-se à ceratectomia superficial de forma lamelar retirando-se um fragmento corneano retangular de aproximadamente $4 \mathrm{~mm}$ × $5 \mathrm{~mm}$ de lado e um terço da espessura da córnea. Imediatamente, igual retalho de peritônio homólogo, conservado em glicerina e previamente hidratado em solução fisiológica, foi suturado à lesão, preocupando-se em manter sua face parietal em contato com o estroma da córnea; realizou-se a síntese utilizando-se polipropileno monofilamentado 7-0* em pontos simples separados de reparo em cada um dos 4 vértices do retângulo. Para a síntese dos lados lançou-se mão também de sutura interrompida em pontos simples separados, utilizando-se nylon monofilamentado 9-0** até que todo implante estivesse adaptado ao defeito corneano.

\footnotetext{
* Prolene 7-() - Cirumédica S.A.

** Superlon 9-0 - Cirumédica S.A.
}

\section{Pós-operatório}

O pós-operatório imediato incluiu aplicação de pomada protetora*** e colocação de colar elizabetano para prevenir automutilação.

Demais medidas incluíram instilação de colírio de Gentamicina**** no saco conjuntival nos primeiros 15 dias subseqüentes ao ato cirúrgico.

Exames oftalmológicos foram realizados sistematicamente para fins de controle das manifestaçōes clínicas, tais como: blefarospasmo, quemose, opacidade e neovascularização da córnea e do enxerto.

Decorridos os tempos preestabelecidos, os animais foram sacrificados, e seus olhos enucleados e fixados em solução de formol a 10\%; fragmentos da região da cómea e implante foram incluídos em parafina e os cortes corados pela Hematoxilina-Eosina para avaliação histológica.

$$
\begin{aligned}
& \text { *** Pomada protetora - Ophthalmos. } \\
& \text { **** Gentamicina Ocullum - Lab. Frumtost S.A. }
\end{aligned}
$$

\section{RESULTADOS}

Com base na análise de 14 córneas, as quais foram submetidas a enxerto xenólogo lamelar de peritônio, pudemos obter os seguintes resultados:

\section{Avaliação clínica}

No período inicial de recuperação abrangendo a primeira semana de pós-operatório, observou-se intensa quemose exceção feita a dois animais - blefarospasmo, prurido, congestão de vasos conjuntivais e secreção ocular mucopurulenta, havendo variação individual na severidade desta última. Todos esses fenômenos foram gradualmente tornando-se menos evidentes, persistindo apenas blefarospasmo a congestão de vasos conjuntivais até aproximadamente o $15^{-}$dia, em média, e dois dos animais persistiram com tal resposta até o $22^{\underline{0}}$ dia.

Opacidade da córnea, representada por edema, não foi reação comum a todos os animais, mas em dois deles mostrouse bastante evidente até o $23^{\circ}$ e o $27^{\circ}$ dia respectivamente. Já o edema corneano nāo mais se fez presente aos 7 dias subseqüentes ao ato cirúrgico.

O teste da fluoresceína foi positivo sobre o enxerto no pósoperatório imediato (Fig. 1.1) e negativo aos 7 dias.

Vasos conjuntivais se tornaram evidentes, invadindo a posição 12 horas do enxerto por volta do $3^{\circ}$ ao $5^{0}$ dia, notandose tecido de granulação mais evidente sepultando os pontos da referida região ao redor do $7^{0}$ dia. Neovascularização marcante até a porção média do enxerto foi observada entre o período correspondente ao $10^{\circ}$ e $15^{\circ}$ dia em média. Proliferaçāo de vasos neoformados em todo o enxerto acompanhou também sua proliferação em córnea ao redor do $15^{\circ}$ dia.

Os fenômenos relacionados à neovascularizaçāo foram mais precoces em dois dos animais, os quais demonstraram maior reação de granulação, antecipando os fenômenos anteriormente descritos em aproximadamente 5 dias. Nessas córneas a neovascularização foi mais evidente, principalmente na porçāo ventral e medial ao enxerto, perpetuando-se até o $30^{\circ}$ dia.

Ao redor do $32^{\underline{0}}$ dia as reaçōes mais exuberantes envolvendo córnea e enxerto foram se tornando menos evidentes, exceção feita à neovascularização da córnea e a proliferação de vasos conjuntivais, os quais se mantiveram presentes até os 60 dias de observaçāo (Fig. 1.2).

Apenas em uma das córneas foi observada pigmentaçāo aos 60) dias de evoluçāo.

No tocante ao enxerto, o tecido de granulação desapareceu em torno de 30 dias, demonstrando aspecto esbranquiçado 
aliado à perda dos sinais de inflamação de todo o globo ocular.

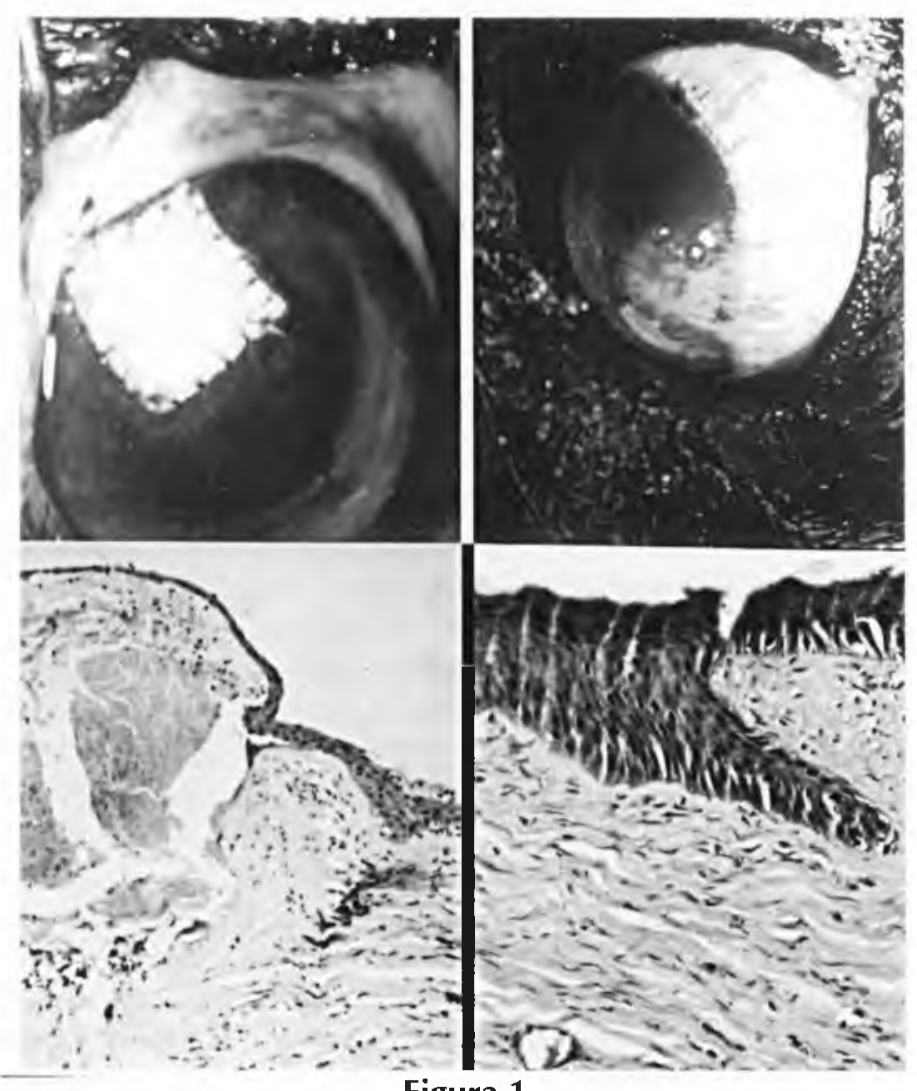

Figura 1

Imagens fotográficas e fotomicrográficas de córnea de cão:

1.1 - teste de fluoresceína, pós-operatório imediato.

1.2- proliferaçāo de vasos conjuntivais e início de desopacificaçāo (60 dias de pós-operatório).

1.3- epitélio corneano invadindo e sobrepondo a área de ceratoplastia, 24 horas de pós-operatório (HE, aumento aprox. $80 x)$.

1.4- facetas epiteliais, 60 dias de pós-operatório (HE, aumento aprox. 160x).

\section{Avaliação histopatológica}

A análise histológica às 24 horas de pós-operatório demonstrou início de epitelização do enxerto homólogo em sua periferia (Fig. 1.3), além de discreto infiltrado inflamatório constituído predominantemente por polimorfonucleares (PMN).

Epitelização total do enxerto associada ainda a infiltrado inflamatório já se fazia presente aos 7 dias.

Um início de reabsorção de enxerto tornou-se claro aos 17 dias, acompanhado de proliferação de vasos neoformados e infiltrado inflamatório basicamente representado por mononucleares.

Aos 32 dias o processo de reabsorção do enxerto já se fazia bastante evidente, tendo o epitélio e o estroma recoberto totalmente o implante, na ausência de processo inflamatório. A magnitude de inflamação não foi comum a todos os animais, haja vista que o infiltrado inflamatório se fez presente em um dos animais até os 60 dias de pós-operatório, aliado à presença de pigmento impregnando o estroma da córnea.

Em uma das córneas, aos 60) dias, notou-se epitélio corneano irregular com células alongadas, agrupadas em paliçada invadindo o estroma (Fig. 1.4); observaram, também, proliferação de vasos neoformados. Contemplando-se ainda o mesmo período, vale ressaltar que não mais se observaram resquícios do enxerto homólogo que foi substituído por estroma corneano.

\section{DISCUSSÃO}

Muitas são as doenças que acometem a córnea, e entre elas merecem destaque as ceratites ulcerativas, porque quando não tratadas, médica ou cirurgicamente, podem causar déficit visual ou mesmo cegueira.

A córnea tem sido alvo de vários estudos, resultando em grande número de técnicas reparadoras.

No concernente ao uso de membranas biológicas, com finalidade de reparação, Kavinski***** em 1980 relatou resultados satisfatórios quando do uso do pericárdio em ceratites ulcerativas. Paralelamente e com o mesmo fim, Barros et $a l^{6}$ (1992) empregaram pericárdio eqüino conservado em glicerina, objetivando reparação cirúrgica de lesōes corneanas na espécie canina com resultados animadores.

Quemose foi manifestação clínica evidente no pósoperatório imediato, incluindo os 3 primeiros dias, sendo a aplicação de reparo conjuntival e blefarostato acusados pela ocorrência de tal resposta. A ausência dessa manifestação, além de secreção ocular mucopurulenta e prurido em dois dos animais, nos leva a crer que existe uma variação individual na resposta inflamatória. Vale ressaltar, ainda nesta fase inicial, que nas 24 horas após a cirurgia, histologicamente, já se observava início de reepitelização do enxerto homólogo, que se concluiu aos 7 dias, fato este comprovado pelo teste da fluoresceína negativo.

Blefarospasmo, reação igualmente presente e comum a todos os animais, manifestou-se durante aproximadamente 15 dias, analogamente ao observado por Barros et al. ${ }^{\circ}$ (1992). Atribuiu-se o blefarospasmo ao contato da conjuntiva palpebral com os pontos na córnea e enxerto.

Remissão da resposta foi satisfatória e sensível após 24 horas da retirada dos pontos em um dos animais. Com o mesmo fim, Laforge ${ }^{21}$ (1993) sugere que os pontos sejam retirados por volta da $3^{\mathbf{a}}$ semana de pós-operatório, quando se utiliza de enxertos conjuntivais pediculados ou não. Proliferação de tecido de granulação sepultando os pontos aplicados na córnea contribuiu sensivelmente para a diminuição do blefarospasmo.

Contrariamente ao observado por Barros et al. ${ }^{6}$ (1992), opacidade de córnea, representada por edema, se fez presente em dois dos animais até o $23^{\underline{0}}$ e o $24^{\underline{0}}$ dia respectivamente, 
havendo sensível prejuízo da visão, haja vista que em um deles tal manifestação acompanhou toda a extensão da córnea, o que pode ser atribuído à falha na técnica operatória nestes dois animais.

No tocante à proliferação de vasos neoformados, nossos achados, clínico e histopatológicos, foram semelhantes aos de Wilkie, Wolf ${ }^{36}$ (1991) e Barros et al. ${ }^{6}$ (1992), os quais se fizeram presentes por volta de 10 dias, e em alguns casos tal fenômeno foi mais precoce. Aos 15 dias, neovascularização do enxerto expressa por tecido de granulação, acompanhando sua manifestação em córnea, se fez presente. Contrariamente, Barros et al. ${ }^{\circ}$ (1992) observaram tecido de granulação mais evidente aos 20 dias.

A opacidade do enxerto se fez presente durante os 60 dias de experimentação. De forma similar foram as observações de Barros et $a l^{6}{ }^{6}$ (1992), os quais relataram diminuição da opacidade parcial do enxerto por volta de 100 dias de pósoperatório.

A deposição importante de pigmento observada aos 60 dias em uma das córneas teria sido evitada com o uso de corticosteróides tópicos a partir da reepitelização do "conjunto córnea-enxerto". Histologicamente esse período foi caracterizado, em alguns cortes, pela presença de células epiteliais alongadas invadindo o estroma subjacente. Tais "estruturas", conhecidas como facetas epiteliais, indicam franca reparação da lesão inicial.

Contrariamente a Wilkie; Wolf ${ }^{36}(1991)$ e analogamente a Barros et al. ${ }^{6}$ (1992), os enxertos de peritônio não foram retirados de seu sítio de implantação, pois houve nítida integração com os tecidos circunvizinhos.

Durante a fase experimental a perda de duas das córneas de um mesmo animal se deu por automutilação, devido, provavelmente, ao intenso prurido manifesto durante as fases iniciais de recuperação. Uma terceira córnea foi desprezada devido à deiscência de dois pontos nos vértices inferiores do enxerto. A opacificação da córnea, que ocorreu possivelmente por não haver uma reparação "ad integrum" do tecido corneano com relação ao arranjo de suas lamelas, não invalida a sua utilização, sendo indicada principalmente nas lesões periféricas da córnea.

Em face das observações factuais das manifestações clínicas e histopatológicas, as quais não expressaram sinal de rejeiçāo, associadas, outrossim, à facilidade de obtenção, conservação e principalmente manipulação dessa membrana biológica, acreditamos que o implante de peritônio homólogo possa vir a fazer parte do rol de técnicas alternativas para reparação de defeitos lamelares corneanos na espécie canina.

***** Kavinski, L.C. (Universidade Federal do Paraná). Comunicação pessoal. Paraná, 1980.

\section{SUMMARY}

The aim of this paper was to study the use of glycerol preserved, homologous peritoneum on the repair of superficial lesions of the cornea. Seven dogs, males and females, weighing about $10 \mathrm{~kg}$ were used. A lamelar keratectomy - 0.4 $\times 0.5 \mathrm{~mm}$ and one third of cornea thickness - was performed at both sides and during the same anesthetic period. A piece of peritoneum was implanted by using a simple, interrupted pattern suture of 8-0 prolene. The animals were sacrificed and eyes were enucleated at 24 hours, 7, 15, 30 and 60 days after surgery. Clinical and histological exams were conducted. Blefarospasm, quemosis and corneal opacity were clinical signs observed at short-term periods. These signs disappeared at day 32, when deopacification of the implant was seen. No inflammation signs were observed at this time. The epithelium had grown over the implant at day seven, and initial resorption of the peritoneum was occurring. No inflammatory infriltrate was seen at day seventeen. Pigment deposition was seen on later evaluations. There were no rejection signs. The results allowed us to admit adopting the homologous preserved peritoneum as another option for keratoplasty in dogs.

UNITERMS: Cornea; Grafts; Dogs; Peritoneum; Corneal transplantation.

\section{REFERÊNCIAS BIBLIOGRÁFICAS}

1-ALVARENGA, J.; BARROS. P.S.M.; IWASAKI. M.; STOPIGLIA, A.J.: GUERRA, J.L. Oesophagoplastie lors de l'ablation de nodules parasitaires chez le chien. Le Point Vétérinaire, v.17, n.94, p.701-2, 1986.

2-BARNET, K.C. The corneal ulcer. VI. Surgical treatment. Journal of Small Animal Practice, v.7, n.4, p.275-7, 1966.

3-BARROS, P.S.M.; ALVARENGA, J; STOPIGLIA, A.J. The use of pericardium in the correction of entropin and the filling of the canine orbital cavity following enucleation. International Society of Veterinary Ophthalmology Newsletter. v. 3, n. 1, p. 4,1985 .
4-BARROS, P.S.M.; BURNIER JUNIOR. M.; RIGUEIRO, M.; MALERBA. T.A.; SAFATLE, A.M.V. The repair of the sclera and $3^{\text {rd }}$ eyelid using heterologous pericardium. A experimental study. In: AMERICAN SOCIETYY OF VETERINARY OPHTHALMOLOGY AND INTERNATIONAL SOCIETY OF Veterinary OPHTHalmology, San Francisco, 1990. Program. p.11-2.

5-BARROS, P.S.M.; SAFATLE, A.M.V.; MALERBA, T.A.; BURNIER JUNIOR, $M$. The surgical repair of the cornea of the dog using pericardium as a keratoprothesis. Brazilian Journal of Veterinary Research and Animal Science, v.32, n.4, p.251-5, 1995.

6-BARROS, P.S.M.; SAFATLE, A.M.V.; RIGUEIRO, M. Implante de pericardio xenologo em cornea de perro: estudio experimental. In: CONGRESO PANAMERICANO DE CIENCIAS VETERINARIAS, 13, Chile, 1992. Resumos. p.0163. 
GARCIA, J.A.; BARROS, P.S.M.; LAUS, J.L.; FERREIRA, A.L.; SAFATLE, A.M.V. Implante de peritônio homólogo conservado após ceratectomia lamelar em cães. Braz. J. vet. Res. anim. Sci. São Paulo, v.33, supl., p.290-294, 1996.

7-BERNIS, W.O. Partial penetrating keratoplasty in dogs. Southwestern Veterinary, v. 15, n. 1, p.30-44, 1961 .

8-CARDONA, H. Keratoprothesis, acrylic optical cylinder with supporting intralamellar plate. American Journal of Ophthalmology. v.54, p.284-6, 1962.

9-DALECK, C.R.; GANDOLFI, W.; DALECK, C.L.M.; ALESSI, A.C. Esofagoplastia cervical no cão com peritônio autólogo ou homólogo conservado $\mathrm{em}$ glicerina. Estudo experimental. Ars Veterinaria, v.3, n.2, p. 195-202, 1987

10-DICE II. P.F.; SEVERIN, G.A.; LUMB, M.V. Experimental autogenous and homologous corneal transplantation in the dog. Journal of the American Animal Hospital Association, v.9, n.3. p.245-69, 1973.

11-HACKER, D.V. Uses of frozen corneal grafts in veterinary ophthalmology. Animal Science Program American College of Veterinary Ophthalmology. v. 15, n. 1, p. $34,1988$.

12-HACKER, D V - MURPHY, C. . LLOYD, K.C.K ; BELLHORN, R.W. Surgical repair of collagenolytic ulcerative keratitis in the horse. Equine Veterinary Journal, v.22, n.1, p.88-92, 1990.

13-HAKANSON, N.E.; MERIDETH, R.E. Conjunctival pedicle grafting in the treatment of corneal ulcers in the dog and cat. Journal of the American Animal Hospital Association. v.23, n.6, p.641-8, 1987.

I4-IIELPER, L.C. Magrane's canine ophthalmology. 4.ed. Philadelphia, Lea \& Fchiger, 1989.297p.

15-HELPER, L.C.; BLOGG, J.R. A modified third eyelid flap procedure. Journal of the American Animal Hospital Association, v.19, n.6, p.955-6, 1983.

16-HERMANN, K. Terapeutic use of hydrophilic contact lenses. In: KIRK, R.W.; BONAGURA, J.D. (ed.). Current veterinary therapy. Small Animal Practice. Philadelphia, W.B. Saunders, 1989. p.640-1.

17-KERN, J. Ulcerative keratitis. Veterinary Clinics of North America. Small Animal Practice, v.20, n.3. p.643-65, 1990.

18-KOENING, S.B.; KAUFMANN, H.E. The treatment of necrotizing scleriting an autogenous periosteal graft. Ophthalmic Surgery, v.14, p.1029-32, 1983.

19-KUHNS, E.L. Conjunctival patch grafts for treatment of corneal lesions in dogs. Modern Veterinary Practice, v.60, n.4, p.301-5, 1979.

20-LAFORGE, H. Pathologic de la cornée chez les carnivores doméstiques. Recueil de Médecine Vétérinaire, v. I65, n.3, p.247-56, 1989.

21 -LAFORGE, H. Diagnóstico y tratamiento de las úlceras corneales. Foccus, v.3, n. 1, p.2-8, 1993.

22-LAUS, J.L.; ROSSI, M.A.; SOUZA, M.S.B.; BARROS, P.S.M.; MORALES, A. Avaliação dos efeitos de um novo adesivo para fins biológicos (Colagel) na ceratoplastia experimental em cảes. Brazilian Journal of Veterinary Research and Animal Science, v.30, p. 183-93, 1993. Suplemento.

23-MORALES, A.; LAUS, J.L.; SOUZA, M.S.B.; CAVALCANTI NETO, F.F. Comparação entre enxertos livres e pediculados de conjuntiva em ceratoplastias experimentais no cão. In: CONGRESSO BRASILEIRO DA ANCLIVEPA, 15. Rio de Janeiro, 1993. Resumos. p.71

24-NASISSE, M.P. Canine ulcerative keratitis. Compendium on Continuing Education, v.7, n.12, p.686-701, 1985

25-NELSON, D.L.; MacMILLAN, A.D. Doenças da córnea. In: KIRK, R.W. (ed.). São Páulo, Manole. 1988. p.808-17.

26-PARSHALL, C.J. Lamellar corneal-scleral transposition. Journal of the American Animal Hospital Association, v.9, n.3, p.270-7, 1973.

27-PEIFFER, R.L.; NASISSE, M.P.; COOK, C.S.; HARLING, D.E. Surgcry of the canine and feline orbit, Adnexa and Globe Part 6: Surgery of the cornea. Companion Animal Practice Ophthalmology, v.1, n.7, p.3-13, 1987.

28-PERUCCIO, C.; BOCIO, P.; CORNAGLIA, E. Indications and limits of cyanoacrylate tissue adhesive in corneal ulcers and perforantions. Animal Science Program American College of Veterinary Ophthalmologists, v. 14, p. $135-53,1983$
29-PIPPI, N.L.; SAMPAIO, A.J.S.H. Estudos preliminares sobre o comportamento do Biofill na ceratoplastia lamelar em coelhos. In: CONGRESSO BRASILEIRO DA ANCLIVEPA, 13., Gramado, 1990. Resumos, p.5.

30-POWEL, N.G. Cirurgia da córnca. In: BOJRAB, M.J. (ed.) São Paulo, Roca. 1986. p.66-71.

31-SLATTER, D. Fundamentals of veterinary ophthalmology . 2.ed. Philadelphia. W.B. Saunders, $1990.668 \mathrm{p}$

32-SOUZA, M.S.B.: LAUS, J.L: CAVALCANTI NETO, F.F.; MORALES, A Comparaçāo entre ceratoplastias lamelares por enxertos autólogos e conjuntiva. Esludo experimental em căes (Canis familiaris). In: CONGRESSO BRASILEIRO DA ANCLIVEPA, 15., Rio de Janeiro, 1993. Resumos. p.73.

33-STARTUP, F.G. The treatment of corneal ulcers. Journal of Small Animal Practice, v.13, n.10, p.601-6, 1972.

34-STOPIGLIA, A.J.; ALVARENGA, J.; BARROS, P.S.M.; GUERRA, J.L. IWASAKI, M. Réparation chirurgicale de la paroi toracique du chien. Le Point Vétérinaire, v.18, n.95, p.239-43, 1986

35-VAUGHAN, D.; ASBURY, T, Oftalmologia geral. São Paulo, Ed. Universidade de São Paulo, 1977. 330p.

36-WILKIE, D.A.; WOLF, E.D. Treatment of epibulbar melanocytoma in a dog. using full-thickness eyewall resection and synthetic graft. Journal of the American Veterinary Medical Association, v.198, n.6, p. 1019-22, 1991.

37-WOLF, E.D. Conjunctival pedicle graft treatment for equine corneal ulcers. In INTERNATIONAL SOCIETY OF VETERINARY OPHTHALMOLOGY MEETING. Viena, 1991. Abstract, p. 19.
Recebido para publicação: 14/07/95 Aprovado para publicação: 18/09/96 